\title{
Las mujeres andinas y el mundo hispánico: descomposición de una sociedad y ritos de supervivencia
}

\author{
Esperanza Mó Romero * y Margarita E. Rodríguez García
}

\begin{abstract}
RESUMEN
ABSTRACT

Al igual que hacian sus dioses y sus diosas, las mujeres y los hombres del mundo andino unieron sus esfuerzos para facilitar la reproducción de sus comunidades. Al modificar los papeles que ambos grupos cumplian, la dominación hispánica puso en peligro la supervivencia de ese mundo. Tras analizar brevemente estos aspectos, nuestro estudio sugiere algunas hipótesis sobre el modo en que las mujeres andinas, desde su nueva

Andean women and men joined their strengths, as their gods and goddesses made, in order to assure the reproduction of their comunities. The survival of this world was put in danger when the Hispanic domination changed the roles they played. After a brief analysis of these points, our study suggests some hypothesis concerning the way Andean women, in their new position, defended their former comunitarian relations.
\end{abstract} posición, defendieron sus antiguas relaciones comunitarias.

Los trabajos centrados en la historia de las mujeres andinas, antes y después de la llegada de los españoles, han insistido en la necesidad de tener muy presente la complementariedad y la interdependencia que existía entre el trabajo masculino y femenino. Eleanor Burkett señala que donde el problema básico es sobrevivir, se necesitan con la misma intensidad los esfuerzos de los hombres y los de las mujeres'.

- Universidad Autónoma de Madrid.

- BuRket, E., "Las mujeres indigenas y la sociedad blanca: el caso del Perú del siglo XVl", en Lavrin, A. (cord), Las mujeres latinoamericanas. Perspectivas históricas. México, 1985, pág. 124. 
Para algunos autores, esta complementariedad entre las tareas de los varones y las mujeres era, en los Andes, el reflejo de la relación que unía a sus dioses y diosas. Había divinidades asociadas a lo femenino como Mamacocha y Mamapacha, madre mar y madre tierra respectivamente, o como la luna, que bajo el dominio inca se convierte en la hermana y la esposa del sol; y deidades asociadas con el mundo masculino, como Illapa, el dios del rayo y el trueno que, concebido como un varón que desde el cielo con su honda y porra hacía tronar y llover, era el complemento masculino que necesitaba la Mamapacha para dar su fruto?

En el mundo andino, las mujeres eran las responsables de las ceremonias dedicadas a las divinidades femeninas, mientras que los varones se ocupaban de los rituales relacionados con los dioses masculinos. Con esta división religiosa, ellas lograron el control de la explotación de las parcelas reservadas para la adoración de las diosas.

La existencia de áreas particulares, tanto de las diosas como de las mujeres, se reflejaba también en otros aspectos muy importantes de la organización andina ${ }^{3}$. Un ejemplo es la existencia de la descendencia paralela; una Institución que según Waldemar Espinoza se explica a partir de la creencia de que los varones derivaban del padre y las mujeres de la madre $y$, por lo tanto, ellos heredaban los bienes inmuebles del progenitor y ellas los de su progenitora. Igualmente, a la hora de encargarse del cuidado de la pareja de momias que se consideraba fundadora y tutelar del grupo de parentesco que constituía el ayllu, los varones debian encargarse del cuidado de la momia de su antecesor y las mujeres de la de su antecesora. Por lo arraigada que estaba la descendencia paralela, el Tercer Concilio Limense de 1582 la contempló en uno de sus artículos añadiendo que a partir de entonces los hijos varones llevarían el apellido del padre y las niñas la de su madre. Espinoza señala que esta costumbre ha tenido tanto peso que ha persistido hasta las primeras décadas del siglo xIX y en la sierra ecuatoriana hasta hace poco ${ }^{4}$.

2 Silverblatt, I., Luna, sol y brujas. Género y clase en los Andes Prehispánicos. Cuzco, 1990, págs. 16-23. En la misma obra Silverblatt analiza cómo los incas reestructuraron el cosmos. Las divinidades locales o bien fueron presentadas, como en el caso de la Mamacocha, como descendientes de la luna, divinidad que presidía el universo femenino imperial y que, además, era identificada con la esposa del Inca, la coya, o bien, como en el caso de la Mamapacha fueron incorporadas al panteon oficial de tal modo que, si antes su adoración garantizaba el fruto para la subsistencia de la comunidad, ahora se habia convertido en una benefactora de todo el Tawantinsuyu, págs. 30-49.

3 Silverblatt, I., Luna, sol..., págs. 24-29.

4 Espinoza, W., La civilización Inca. Economia, Sociedad y Estado en el umbral de la Conquista Hispana. Lima, 1990, pág. 149. 
La complementariedad e interdependencia existente entre el trabajo masculino y femenino en el mundo andino era una realidad tal que, bajo el dominio inca las contribuciones en trabajo al poder, conocidas como mita ${ }^{5}$, sólo las realizaban los hombres casados entre 18 y 50 años de edad; lo que implicaba el reconocimiento del valor del trabajo femenino. Mientras se mantenían solteros permanecian en la morada de sus padres, dependiendo de los productos cosechados en la parcela de éstos.

En opinión de Eleanor Burkett, en lugar de decir que el tributo recayó sólo sobre los hombres casados sería más preciso afirmar que éste era una obligación de la casa familiar de la que el varón era el representante. La autora señala que podría contemplarse una división interna del trabajo dentro del hogar, en razón de género, pero todas las actividades serian consideradas esenciales y complementarias puesto que, hasta que el hombre no se casaba y recibía la ayuda de su mujer, no se le consideraba un tributario ${ }^{6}$. Para apoyar esta última idea, Burkett sostiene que varios estudios antropológicos actuales muestran cómo la existencia de las arras (pago que hacía el prometido al padre de la novia con motivo del matrimonio) indica una activa participación económica de la mujer. El hecho de que las arras formaran parte de las costumbres andinas habría de verse, entonces, como «una compensación que se pagaba a la familia nativa por la perdida de un miembro económicamente activo de esa unidad de producción»?

Ahora bien, ¿cómo se reflejó esa valoración del trabajo femenino, y la participación de las mujeres en los rituales, en el ejercicio del poder político en el mundo andino?

La respuesta varía bastante dependiendo del momento y la zona geográfica a la que dirijamos nuestra atención. Está bastante documentada la existencia de mujeres, las capullanas, que ejercían el dominio de sus $c u-$ racazgos, en la región de Piura, en tiempos preincaicos ${ }^{8}$. Sin embargo,

5 La mita era una contribución en trabajo que los campesinos debian cumplir obligatoriamente por turnos y que según Waldemar Espinoza, "generaba rentas al estado cultivando su ganado, explotando sus minas y lavaderos, confeccionando armas, piezas y objetos artesanales o prestando diferentes servicios personales (chasquis, tambos, puentes, caminos, levas de ejército)...", ESPINOZA, W., La civilización Inca..., pág. 232.

6 BuRketT, E. «Las mujeres indigenas...», págs. 123-124.

ibidem, pág. 124.

8 María Rostworowski, a partir del análisis de personajes femeninos pertenecientes al mito y la leyenda y de la existencia de documentos de archivo que revelan la presencia de mujeres $\mathrm{ku}$ raka que ejercían directamente el poder durante los siglos $x V$ y XVI, sostiene que el poder no era un privilegio del varón en el mundo andino. "La mujer en la época prehispánica", en Documentos de Trabajo No 17, Serie: Etnohistoria N¹. Lima 1986. 
otros trabajos mantienen que bajo el dominio inca la mujer no tuvo ninguna participación importante en el poder político ${ }^{9}$.

El territorio andino es muy extenso y generalizar resulta difícil, porque ni siquiera durante el período incaico hubo una unificación total de leyes y costumbres para todo el Tawantinsuyu, como antes se creía.

El dominio hispano produjo una serie de cambios, independientemente de los políticos, en el modo de vida que hasta entonces habían llevado las comunidades. Muchos autores han señalado que, pese a que necesitamos conocer más acerca de lo que representaron para ellas las demandas de las instituciones incaicas, en general, el régimen tributario español puso en peligro la supervivencia del ayllu. Fueron cambios que afectaron tanto a los varones como a las mujeres y queremos destacar los dos que nos parecen mas importantes.

Hasta la llegada de los españoles el tributo no era una tasa fija. Además de consistir en la realización de ciertos trabajos para el poder, requería fundamentalmente el empleo de la energía humana de los comuneros en las tierras y ganados del Incario y de los kurakas y en las destinadas para mantener los cultos. Bajo el dominio colonial, la necesidad de entregar un tributo en especie o en dinero obligaba a los ayllus a hacer esfuerzos adicionales cuando una mala temporada o cualquier otra circunstancia aumentaba la dificultad para conseguir lo demandado por los españoles. Rompía con la norma andina que, para asegurar la subsistencia de los comuneros, impedía tributar de lo propio.

Por otra parte, las instituciones, para facilitar el que la colonia contara con la suficiente mano de obra, mantuvieron la mita prehispánica que como ya hemos señalado, imponía a la población masculina entre $18 \mathrm{y}$ 50 años la realización de trabajos por turnos para el Incario. Se obligó a entregar, como máximo, un séptimo de la población tributaria de un repartimiento, que trabajaría fuera de la comunidad hasta la llegada del siguiente turno. Esta medida pretendía asegurar, siguiendo la costumbre incaica, que ese flujo de trabajadores no perturbara las necesidades laborales de la comunidad. Pero en la práctica, el retraso en los pagos a los trabajadores y el hecho de que existieran mecanismos de retención, como el endeudamiento fruto de la adquisición de mercancías durante la estan-

9 Burkett señala que bajo la dominación de los incas el único camino que las mujeres tenían para mejorar su posición era conseguir ser reclutadas en el acllahuasi o casa de escogidas donde, además dedicarse a la producción de tejidos y chicha, podian corlvertirse en sacerdotisas, mujeres secundarias del inca o servir como recompensa a los soldados, Kurakas y otros servidores del Inca. "Las mujeres indígenas...", págs. 125-126. 
cia, provocaba que, en ocasiones, una mita se juntara con otra y que los trabajadores tardaran en regresar a sus comunidades mucho más de lo previsto.

Si en los mitayos podía crear una sensación de desarraigo, la quiebra de las relaciones sociales significaba para las comunidades que no contarían con la mano de obra prevista para atender los terrenos, el ganado y el resto de las tareas comunitarias. Esto fue minando la autonomía económica del ayllu, pese a que, cómo señala Steve Stern, fuera un proceso lento, especialmente grave a finales del siglo xvı, que las poblaciones indígenas trataron de paliar en un principio "vendiendo aquellos terrenos que tras el descenso demográfico y la huída de mucha población estaba quedando sobrante, trabajando minas locales por cuenta propia, vendiendo cultivos comerciales y mercancías elaboradas como lana y queso o yendo a los tribunales para defender sus derechos" ${ }^{10}$.

Nos interesaba señalar estos dos aspectos porque son una muestra de las presiones que estaba sufriendo la organización comunitaria tradicional y que, por lo tanto, afectaba a toda la comunidad. Pero, además, si recordamos lo que habíamos señalado sobre la etapa prehispánica, el hecho de que bajo el sistema colonial todos los varones indígenas de origen común, entre los dieciocho y cincuenta años, estuvieran sujetos a las exigencias del tributo, independientemente de que estuvieran casados o no ${ }^{11}$, significaba que el sistema tributario español no estaba teniendo en cuenta el profundamente arraigado concepto andino de la unidad doméstica, la complementariedad del trabajo femenino y masculino como la mínima entidad sujeta a tributo.

Los Kurakas, intermediarios ante las autoridades coloniales, tenían que conseguir para éstas el tributo pero, en el interior de sus comunidades y sobre todo en la primera etapa de la colonización, se veían todavía obligados a operar dentro del marco de los valores andinos. Para poder satisfacer las exigencias tributarias hispanas, fueron ellos mismos los que tuvieron que distorsionar las normas indígenas. Por ejemplo, algunos $\mathrm{Ku}$ rakas utilizaron el ardid de casar a los jóvenes antes de que cumplieran la edad apropiada para el matrimonio. Otros obligaban a los hombres a casarse con muchachas que estaban muy por debajo de la edad aceptada, con la finalidad de mantener la ilusión de que eran hombres casados y tributarios. En una visita se recogen las siguientes quejas:

to Stern, S., Los pueblos indigenas del Perú y el desatio de la conquista española. Huamanga, hasta 1640. Madrid, 1986, pág. 149.

Silverblatt, I., Luna, sol..., pág. 93. 
"...el dicho cacique don Gómez los agravió...( a los comuneros)...en darles por mujeres muchachas que no eran para trabajar ni los ayudaban".

"...el cacique don Gomez...cuando repartió los tributos los agravió porque repartio...(a los casados) algunos de los cuales son de dieciocho a veinte años...y que si casaban un indio de quince años y le daban mujer muchacha le repartían tanto como si fuere hombre ya hecho..." ${ }^{12}$.

Todo esto refleja los apuros de los Kurakas para cumplir con las obligaciones tributarias. En ocasiones gravaban a solteros y viudos y éstos se quejaban de que no tenían pareja que los ayudara y, finalmente, a medida que las exigencias del tributo aumentaron, las campesinas también cargaron el peso de los gravámenes hispanos.

La siguiente cita muestra cómo los Kurakas, rompiendo con las normas tradicionales, empezaron a exigir una mayor contribución de las mujeres para poder atender las demandas coloniales.

"...en tiempo del ynga tenian menos trabajo porque las mujeres ni los viejos no trabajaban y les hacian las chácaras ${ }^{13}$ a los que se ocupaban y trabajaban en el tributo y que al presente trabajan todos" ${ }^{14}$.

Pero, no solamente los Kurakas presionaban a las mujeres; también otros representantes del poder colonial reclamaban de ellas diferentes trabajos. El siguiente comentario refleja qué consecuencias podían tener las exigencias de los doctrineros en la organización familiar:

"Para alivio de las indias debe V.M. mandar que los doctrineros no apremien a las mugeres a que ilen ni texan para ellos ni sus allegados con ningún pretexto, por que todo el año las traen fatigadas con tareas, de modo que por no hacerles falta todas las semanas con lo que las han repartido, no tienen tiempo para acudir a sus maridos, ni hixos para guisarles una pobre comida quando estan en su pueblo..." ${ }^{15}$.

En definitiva, aunque bajo la ley española las mujeres nativas se hallaban formalmente exentas del tributo, como se necesitaba el trabajo femenino, éste fue utilizado a pesar de los impedimentos legales.

12 ORTIZ dE ZúNigA, Iñigo, Visita de la provincia de León de Huánuco (1562). Huanuco, 1967, págs. 73 y 78 . Citado por Irene Silverblatt, Luna, sol..., pág. 94.

13 Parcelas de tierra.

14 ORTiz DE ZúNIGA, Iñigo, Visita de la provincia de León de Huánuco. Huanuco, 1972, pág. 35, citado por Silverblatt, I. Luna, sol..., pág. 95.

15 "Alivio de las mugeres indias para que hilen ni texan para los doctrineros", en Descripción General de todos los dominios de la América que pertenecen a S.M. (1683). Biblioteca del Palacio Real de Madrid, Manuscritos de América, II/2537, fols. 119 y 120. 
Otro cambio importante para las mujeres, según Irene Silverblatt, fue que con los españoles, perdieron el acceso autónomo que habían tenido a ciertas parcelas. Según la autora, el hecho de que el Virrey Toledo, en la década de 1570, redujera en pueblos a la población indígena que hasta el momento vivía en un habitat disperso, contribuyó enormemente a ello ${ }^{16}$ : al trasladar a la población, Toledo alteraba las antiguas relaciones sociales y esto, junto con el descenso de la población, indujo a hombres y mujeres de distintos ayllus a casarse entre si, a diferencia de lo que ocurría anteriormente. La consecuencia fue negativa para las mujeres porque al obligar el Virrey a que la pareja estuviera solo sujeta a las exigencias tributarias del ayllu del marido, en el que además debían de residir a partir de entonces, $y$ al señalar que los niños serían considerados exclusivamente como miembros del ayllu paterno, se favorecieron los vínculos patrilineales y patrilocales y se alteraron "los patrones tradicionales de tenencia de la tierra y de la herencia paralela, con los cuales las mujeres mantenían un acceso autónomo a las tierras» ${ }^{17}$.

Hasta aquí hemos tratado de mostrar cómo afectaron a las mujeres los cambios que la dominación hispana impuso a las comunidades ${ }^{18}$. La reacción de las mujeres indígenas ante las dificultades de sus comunidades para asegurar la reproducción de todo el grupo y ante las presiones que por ello recibieron ellas fue, en bastantes ocasiones, la emigración a las ciudades ${ }^{19}$. Pero lo que nos interesa ahora es plantear cual fue la reacción de las que permanecieron en las comunidades.

La primera consideración que habría que preguntarse sería: ¿Qué lugar ocupaban en el sistema colonial hispano?

\footnotetext{
16 Silverblatt, I., Luna, sol..., págs. 97 y 98.

Ibidem, pág. 98.

18 Glave, L.M., Trajinantes. Caminos indigenas en la sociedad colonial. Siglos XVI/XVII, Lima, 1989, pág. 336.

19 En torno a este tema se ha generado una amplia discusión acerca de la relación que estas mujeres mantuvieron con sus comunidades de origen. Autoras como Ann Zulawski o Brooke Larson insisten en la continuidad de las relaciones comunitarias. Sin embargo, otros como Luis Miguel Glave o Eleanor Burkett, sin negar lo anterior, enfatizan el hecho de que el dominio hispano colonial supuso para muchas mujeres la quiebra de las relaciones sociales tradicionales y el nacimiento de nuevas identidades.

ZULAWSKI, A., "Mujeres indigenas y la economía de mercado en la Bolivia colonial" en STOLC$\mathrm{KE}, \mathrm{V} .$, Mujeres Invadidas. La sangre de la Conquista de América, Cuadernos Inacabados 12 , págs. 67-91. LAASON, B. “Producción doméstica y trabajo femenino indígena en la formación de una economía mercantil colonial» en Historia Boliviana, III/2, 1983, págs. 173-188, GLAVE, L.M., "Mujer indígena, Trabajo doméstico y cambio social en el siglo xVIII", en Trajinantes. Caminos indigenas en la sociedad colonial, siglos XVI y XVII. Lima, 1989, págs. 307-362, y BURKETT, E.C., "Las Mujeres indígenas y la sociedad blanca: el caso del perú del siglo XVI", en LAVRIN, A., (coord). Las mujeres latinoamericanas. Perspectivas históricas. México, 1985, págs. 121-152.
} 
La sociedad estamental que los castellanos trasplantaron a América estaba concebida como una sociedad de inclusiones y exclusiones en función del estatus que se poseía. La población indígena por su condición de menores, rústicos y miserables ${ }^{20}$ quedaba relegada a una posición de subordinación al considerárseles como un grupo necesitado de amparo y protección por parte de las autoridades coloniales.

Algunos de los varones, por su condición de Kurakas, mantenian sus privilegios y todos, en tanto que tributarios, quedaban registrados en los documentos coloniales. Sin embargo, las mujeres indígenas sumaron a su estatus de Indias la subordinación por cuestión de género que las catapultaba a una posición más invisible y secundaria.

En la Península, las mujeres sólo tenían cabida dentro de la familia bajo la autoridad ilimitada del Pater familias, que sólo rendia cuentas de su conciencia ante Dios. Por ello resulta dificultoso documentar la actuación de las mujeres fuera de ese mundo doméstico, porque cualquier actuación legal suya necesitaba de la tutela y representación de un varón. Este esquema de pensamiento es el que se trasladó a América y se aplicó a las mujeres indígenas, dando lugar a una categoría de menores entre menores.

A la vez que se les otorgaba esa situación jurídica, se les exigía, sobre todo tras la introducción de los preceptos tridentinos después del lller Concilio Limense, valores de pureza, castidad y honorabilidad diferentes a los suyos indígenas.

La articulación del mensaje religioso que legitimaba la presencia hispana en América se establecía mediante la imposición de unos preceptos morales cristianos que dirigian la vida de las comunidades y sobre todo la de las mujeres. Sobre ellas se impusieron las mayores restricciones a través del mundo del matrimonio, la definición del pecado, y toda una larga serie de preceptos que se imprimieron en las conciencias indígenas por la vía del confesor. La religión católica fue el principal reflejo de la dominación hispana en el interior de las comunidades y el confesor fue uno de los protagonistas del intento postridentino de controlarlas. Por ello, los memoriales de los religiosos son una de las mejores fuentes para acercarse al mundo del ayllu y a las mujeres indígenas.

Después del Concilio los manuales de confesores se volvieron más metódicos y nada escapa a la mirada y al escrutinio del religioso encargado de la comunidad. Se exigía que las confesiones fuesen profundas y

\footnotetext{
20 Clavero, B., Derecho indigena y cultura constitucional en América. México, 1994, págs. 11-20
} 
concretas, es decir que no supusiesen una mera formalidad, Alonso de la Peña en su Itinerario para párrocos de indios, señala que:

"las personas virtuosas que no saben mucho, y más las mujeres, suelen de ordinario se prolijas, cargándose de preámbulos, generalidades e imperfecciones que no son materia de confesión... particularmente cuando a la relación prolija de sus culpas juntan las historias, cuentos e importunios, relaciones pesadas y razones impertinentes... otras por no hallar culpa que confesar dicen unas generalidades tomadas de memoria. Otras, después de gran rato que dicen y dicen, no han dicho nada ni han dado materia al confesor para que las absuelva. Por tanto conviene enseñarlas»" ${ }^{21 .}$

En esta cita se puede observar claramente cómo a la imagen de ignorancia del indio se sumaba la concepción de las mujeres en general como seres ambiguos, cuya inocencia y falta de conocimientos podia servirles para escapar al control de los doctrineros.

Las indígenas habian quedado, para las autoridades coloniales, relegadas al mundo doméstico. Sin embargo, si antes de la llegada de los españoles tuvieron posiblemente una participación abierta en las actividades de carácter político y sobre todo religioso de la comunidad, ahora pudieron, desde ese puesto menos visible, mantener y hasta fomentar las costumbres y ritos tradicionales. Irene Silverblatt opina que, incluso, cobraron un papel protagonista en algunos cultos en los que antes participaban de forma secundaria.

Las explicaciones pueden ser varias, en primer lugar no era extraño que los varones huyeran para evadir el tributo o que se ausentaran de la comunidad para cumplir algún servicio mientras que ellas permanecian en sus pueblos natales y seguramente serían las más interesadas en afirmar los lazos comunitarios. Pero sobre todo, al darle sólo a los varones la posibilidad de participar en las instituciones políticas y religiosas coloniales se empujó a las mujeres «hacia las prácticas tradicionales que el régimen

\footnotetext{
21 De la Peña Montenegro, Alonso de, Itinerario para párrocos de indios. Madrid, 1996, libros III y IV, págs. 106-107, refiriéndose a una cita de BERMúdEZ DE CASTRo, Francisco, Reformación cristiana. Sevilla, 1625. Nos parece oportuno señalar que en estas fuentes religiosas, manuales de contesores, campañas de extirpación de idolatrías, cartas de religiosos...indirectamente podemos encontrar muchas de las claves que nos explicarán los comportamientos de las mujeres indígenas. Así mismo los procesos de inquisición, aunque ésta no actuó directamente con las indias por su condición de neófitas en la fe, pueden ofrecernos también datos muy interesantes. Las mujeres indigenas aparecen por una parte como proveedoras de filtros, hierbas y hechizos a mujeres españolas, y por otra como responsables de la educación de sus hijas mestizas procesadas por la Inquisición. Para más información sobre este último punto ver, MEDINA, M. A., Op, Doctrina cristiana para instrucción de los Indios por Pedro de Córdoba. México 1544-1548, Salamanca, 1987. LIENHARD, M., Testimonios, cartas y manifiestos indigenas. Caracas, 1992.
} 
dominante definía como diabólicas» ${ }^{22}$. Ellos, en una posición más visible, debian esconder más firmemente sus prácticas «idolátricas».

¿Cómo fueron interpretadas estas actividades por las autoridades? Los europeos trasladaron al Nuevo Mundo sus ideas acerca de la lucha eterna entre las fuerzas del bien y del mal. Sólo la presencia del demonio podía explicar en América el culto a los árboles, a las piedras o al sol ${ }^{23}$. Las mujeres, a la vez que eran vistas como seres débiles eran también concebidas como poderosas: la propia debilidad les otorgaba, a los ojos de los varones, un poder clandestino, porque eran fácilmente susceptibles a las tentaciones del maléfico.

De este modo, toda una serie de prácticas precolombinas, llevadas a cabo por mujeres, empezaron a ser interpretadas como brujería ${ }^{24}$. Contribuyeron a esta valoración tanto el género de las acusadas como la atribución que en la península se hacía de upeligrosos poderes ocultos a los grupos desprovistos de poder y conquistados, ya fuesen indígenas 0 moros" 25.

Sin embargo, si ésta era la valoración que se hacía desde el mundo hispano, en las comunidades la práctica de los rituales antiguos supuso una afirmación de su papel como organizadoras y mantenedoras de las relaciones comunitarias.

Irene Silverblatt ha analizado el significado que podía tener, en el mundo de las comunidades indigenas sometidas al poder colonial, el ejercicio de ritos tradicionales.

Su tesis es que algunas "brujas" se convirtieron en voceras y defensoras de las reglas normativas de la vida aldeana. Una de ellas, Juana Icha, mujer que tenia fama de auxiliar a los hombres que acudian a trabajar a las minas de Potosí o a las refinerías de azúcar, fue acusada de amenazar al alcalde con que el diablo iba a pasarle la cuenta por haber azotado a una de sus hijas. En las otras ocasiones en las que Juana había intervenido, se trató, por ejemplo, de ayudar a una mujer a evadir al mayordomo de un cura doctrinero o de hechizar a un cobrador de tributos.

\footnotetext{
22 Silverblatt, I., "El arma de la hechicería”, en Stolcke, V., Mujeres invadidas..., págs. 155-

23 Fray Juan de San Pedro, La persecución del demonio, Crónica de los premeros agustinos en el Norte del Perú (1560), con estudios preliminares de Luis Millones, John R. Topic y José L. González. Málaga, 1992, pág. 13.

24 Silberbi.ATt, I., "El arma de ...", en Stolcke, V., (comp), Mujeres invadidas..., págs. 130140.

25 BEHAR, R., "Brujería sexual, colonialismo y poderes de las mujeres: su reflejo en los archivos de la Inquisición Méxicana”, pág. 186, en StolCKE, V., (comp), Mujeres invadidas..
} 156. 
Silverblatt señala que los cargos presentados en contra de Juana muestran que sus ataques estaban dirigidos contra hombres que supuestamente habian abusado de su posición de poder en la sociedad colonial "desafiando las tradicionales expectativas andinas sobre la conducta de las autoridades comunales". La autora presenta varios casos más de mujeres que fueron acusadas de preparar bebedizos para hombres que siempre tenían alguna posición de autoridad.

Ese papel de protectoras de las tradiciones y reglas de la aldea, que Silverblatt atribuye a las "hechizeras", porque castigaban a los que violaban abiertamente las normas comunitarias, resulta coherente con algunas de las prácticas religiosas andinas que siguieron desarrollándose bajo el dominio colonial.

Tanto el jurista Polo de Ondegardo ${ }^{26}$ como el jesuita y extirpador de idolatrías, Arriaga, mencionan la "confesión idolatra" a la que debían someterse los indígenas de la comunidad. Ambos coinciden en señalar que ésta era llevada a cabo tanto por hombres como por mujeres. Lo interesante es que, en la apreciación de Arriaga, los indígenas se acusaban de haber tenido actitudes anticomunitarias, de haber incumplido normas de convivencia ${ }^{27}$.

"no confiesan pecados interiores, sino de haber hurtado, de haber maltratado a otros, tener más de una mujer...acúsanse de haber ido a reverenciar al Dios de los españoles y de no haber acudido a las huacas" ${ }^{28}$.

Polo de Ondegardo señala que bajo el dominio inca, además de toda esa serie de faltas contra la comunidad que ya hemos mencionado, “...por muy notable pecado tenían el de cuydo en la veneración de sus Huacas, y el quebrantar sus fiestas y el decir mal del Inga y el no obedecerle..." ${ }^{29}$. Este autor presenta siempre al Incario como un poder que controlaba ferreamente la vida de las comunidades, en este caso, por medio de la confesión.

\footnotetext{
26 POLO DE ONDEgARDO, Tratado y averiguación sobre los errores y supersticiones de los indios, Colección de libros y Documentos referentes a la historia del Perú, Tomo III. Lima, 1916, pág. 12.

27 Pérez Canto, P., "Las muchas caras de la idolatría», en Fernandez Albaladejo, P y otros (coord), Política, religión e inquisición en la España moderna en homenaje a Joaquín Pérez Villanueva. Madrid, 1996 pág. 558.

28 Arriaga, Pablo José de. Extirpación de la idolatria del Pirú, en BAE, T. 209. Madrid, 1968, pág. 212. Citado por PÉREZ Cantó, P. op. cit.

29 POLO de ONDEGARDO, Tratado y averiguación sobre los errores y supersticiones de los indios, Colección de libros y Documentos referentes a la historia del Perú, Tomo Ill. Lima, 1916, págs. $12-13$.
} 
Sin embargo, ya mencionábamos al principio de esta comunicación que esta imagen debe ser muy matizada, Polo, al hablar de las hechicerías, señala que son practicadas tanto por hombres como por mujeres pero señala que aquellos que son

\begin{abstract}
"...diestros en hazer confectiones de yervas, y rayzes para matar al que las dan...son casi siempre mugeres...Y en sintiéndose alguno enfermo acude luego a estos hechizeros para que deshagan el daño, que sospechan averseles hecho por algún mal suyo...Por lo cual son estas hechizeras en gran manera temidas aun de los caziques...Ni los Indios osan descubrirlas, de temor porque lo vno temen ser hechizados de nuevo y lo otro de que también ellas manifestarían los males suyos. Este género de hechizeros de poncoña castigavan los Yngas matando los tales hechizeros hasta sus descendientes" ${ }^{30}$.
\end{abstract}

El relato del Licenciado nos transmite varios estereotipos sobre la función que tenía la manipulación de hierbas. Por un lado se atribuye a las mujeres el conocimiento de como mezclarlas para un determinado fin y además, se da por supuesto que la manipulación de esas sustancias llevaba parejo provocar algún daño. De nuevo aparecen las mujeres como el grupo que más fácilmente acudía a éstas pócimas para envenenamientos premeditados. Nos resulta difícil apartar la interpretación que hace este autor y otros muchos, de lo que estas mujeres representaban en la comunidad, porque tal vez, los miembros de la comunidad acudían a ellas como sanadoras. Pero, ¿por qué los Incas reprimieron a algunas de ellas de manera tan severa? ¿Interpretaron que éstas mujeres podían suponer un peligro para su dominio?

Las Crónicas nos refieren un complejo mundo de prácticas comunitarias a las que se fueron enfrentando. En los primeros momentos permitieron algunas de ellas, pero la ortodoxia tridentina impuso una visión más severa de las costumbres indígenas, todo fue visto con otros ojos.

El nivel de exigencias se hizo más complejo, los ritos indígenas se consideraron como ritos de brujería, por tanto de inversión de la doctrina cristiana y habia que convencer a los feligreses de la bondad del mensaje de Cristo. Todas esas prácticas fueron consideradas como tratos con el demonio y por tanto de resistencia al orden social. De ahí la necesaria persecución de sus protagonistas. El confesionario se convirtió en uno de los caminos para averiguar, a través de preguntas precisas, quiénes continuaban con éstas prácticas. Las mujeres que los españoles calificaban como hechiceras se negaban a acudir a misa o a la doctrina. Deberemos seguir investigando sobre lo que representaron estas mujeres andinas en las comunidades a lo largo del tiempo.

$30 \quad$ Ibidem, pág. 28. 